Full paper

\title{
New Hydrodynamic Electrochemical Arrangement for Cadmium Ions Detection Using Thick-Film Chemical Sensor Electrodes
}

\author{
Jan Prasek ${ }^{1}$, Martin Adamek ${ }^{1}$, Jaromir Hubalek ${ }^{1}$, Vojtech Adam ${ }^{2}$, Libuse Trnkova ${ }^{3}$ and \\ Rene Kizek $^{2, *}$
}

1 Department of Microelectronics, Brno University of Technology, Brno, Udolni 53, CZ-602 00 Brno, Czech Republic; e-mails: prasek@feec.vutbr.cz, adamek@feec.vutbr.cz,hubalek@feec.vutbr.cz

2 Department of Chemistry and Biochemistry, Mendel University of Agriculture and Forestry, Zemedelska 1, CZ-613 00 Brno, Czech Republic

3 Department of Theoretical and Physical Chemistry, Faculty of Science, Masaryk University, Kotlarska 2, CZ-611 37 Brno, Czech Republic

* Author to whom correspondence should be addressed; E-mail: kizek@sci.muni.cz

Received: 16 October 2006 / Accepted: 27 October 2006 / Published: 6 November 2006

\begin{abstract}
Miniaturization and integration of chemical devices into modules that are dimensionally comparable with electronic chips (Lab on Chip) is nowadays developing worldwide. The aim of our work was to suggest and optimize the best conditions for fabrication of TFT sensor due to its sensitivity and low experimental deviations. New electrochemical analytical device was developed to ensure certain known mass transport to electrodes, which is the most limiting process that influencing the response quality of the sensor. The device consists from rotating conic vessel for measured sample and stick-in thick-film sensor. The sensors responses were tested under trace analysis of cadmium. Measurements were done also with the others electrochemical arrangements to compare with the new one. The sensor output current response dependence on the liquid velocity and geometrical arrangement within using standard electrochemical couple of potassium ferrocyanide-ferricyanide is presented. We found out that the new device with controlled flow of electrolyte to sensor worked properly and gave satisfactory results.
\end{abstract}

Keywords: flow analysis, differential pulse voltammetry, cadmium, thick-film sensor. 


\section{Introduction}

Miniaturization and integration of chemical devices into modules that are dimensionally comparable with electronic chips (Lab on Chip) is nowadays developing worldwide [1-7]. These devices have miniature cross-sectional area of the electrodes and are capable to work with minimal volumes and amounts of electrolytes. Thus, these devices can be utilized widely for purposes where using of expensive chemicals such as enzymes, antidotes or hormones are needed [8,9].

Electrochemical sensors consisted from various types of electrodes have been using for suggesting of the above-mentioned devices very often. Suggesting and developing of new types of solid electrodes are needed for small device technologies contrary to standard electrochemical analysis, where mercury drop electrodes have been commonly using. Solid electrodes can be fabricated by thick-film technology (TFT) process [10,11]. Its flexibility, good reproducibility and good electrical and mechanical properties of electrodes are the advantages of TFT process. Moreover, the crucial advantage lies in low cost of electrodes (e.g. platinum electrode containing $1 \mathrm{mg}$ of Pt) used, whereas these electrodes can be used for a few analyses only. In spite of high variability of materials used for fabrication of the electrode, which is consisted both from metals such as Pt, Au, Ag and semi conductive materials, magnetic and reproducible nanostructured electrodes are prepared [5,12-15].

Based on the abovementioned facts and thousands of papers published [16-20], the sensors have superior properties over the other existing measurement systems because they could provide quick, simple and low-cost on-field determination of many biologically active compounds, number of dangerous pollutants and many others organic and/or inorganic species [21-30]. Heavy metals ( $\rho>5$ g.cm-3) such as lead, mercury and cadmium are one of the most toxic and undesirable compounds polluting agricultural products [31-33]. Cadmium and solutions of its compounds are extremely toxic even in low concentrations, and tend to bioaccumulate in organisms and ecosystems. One possible reason for its toxicity is that it interferes with the action of zinc-containing enzymes [34-38]. Inhaling cadmium laden dust quickly leads to respiratory tract and kidney problems which can be fatal (often from renal failure). Ingestion of any significant amount of cadmium causes immediate poisoning and damage to the liver and the kidneys [39-41]. Due to cadmium possessing as a threat to organisms, the suggesting, developing and optimizing analytical tools for its determination is very need. A number of techniques including both robust hyphenated instruments and small analytical devices have been used for these purposes [21,22,42-50].

The aim of our work was to suggest and optimize the best conditions for fabrication of TFT sensor due to its sensitivity and low experimental deviations. This sensor has been consequently utilized for determination of cadmium.

\section{Experimental}

\subsection{Chemicals}

All chemicals used were purchased from Sigma Aldrich (St. Louis, USA), unless noted otherwise. Solution of a $0.05 \mathrm{~mol} / \mathrm{L}$ potassium ferrocyanide $\mathrm{K} 4 \mathrm{Fe}\left(\mathrm{CN}_{6}\right), 0.05 \mathrm{~mol} / \mathrm{L}$ potassium ferricyanide 
$\mathrm{K} 3 \mathrm{Fe}\left(\mathrm{CN}_{6}\right), 0.2 \mathrm{~mol} / \mathrm{L} \mathrm{KOH}, 0.1 \mathrm{~mol} / \mathrm{L} \mathrm{KCl}$ and $10 \mathrm{mmol} / \mathrm{L} \mathrm{CdCl}_{2}$ were prepared using $18 \mathrm{M} \Omega$ redistilled and deionized water (taken from Direct-Q Water Purification System, Millipore).

\subsection{Screen-printed electrodes preparation}

The TFT sensor was fabricated by using a standard TFT process with screen-printing semi automat (UL 1505A, TESLA, CZ) and firing oven (TFF51, BTU International, USA), whereas the scheme of fabricated device is shown in Fig. 1. The TFT materials used for reference (Ag/AgCl), auxiliary electrode (carbon) and conductive layer were ESL 9912-D paste, dielectric layer ESL 4913-G paste and working electrode ESL 8881-B Au paste (all ESL ElectroScience, UK). All pastes were fired according to producer's recommendations described in datasheets. The reference electrode was calibrated against saturated Ag/AgCl electrode (Fig. 2).

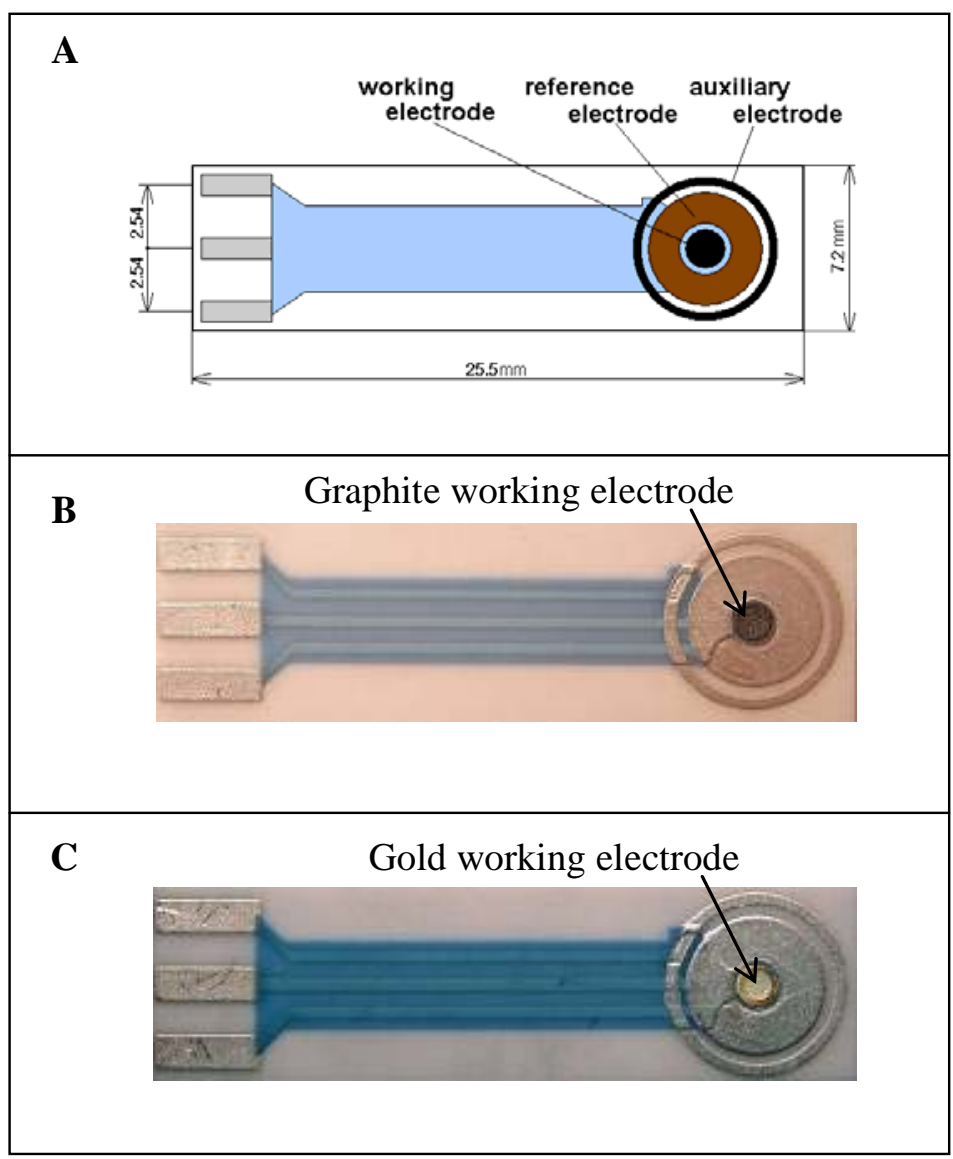

Figure 1. Thick-film technology (TFT) sensor design (A) and real TFT sensor with reference (Ag/AgCl) electrode, carbon auxiliary electrode and graphite (B) or gold (C) working electrode. 


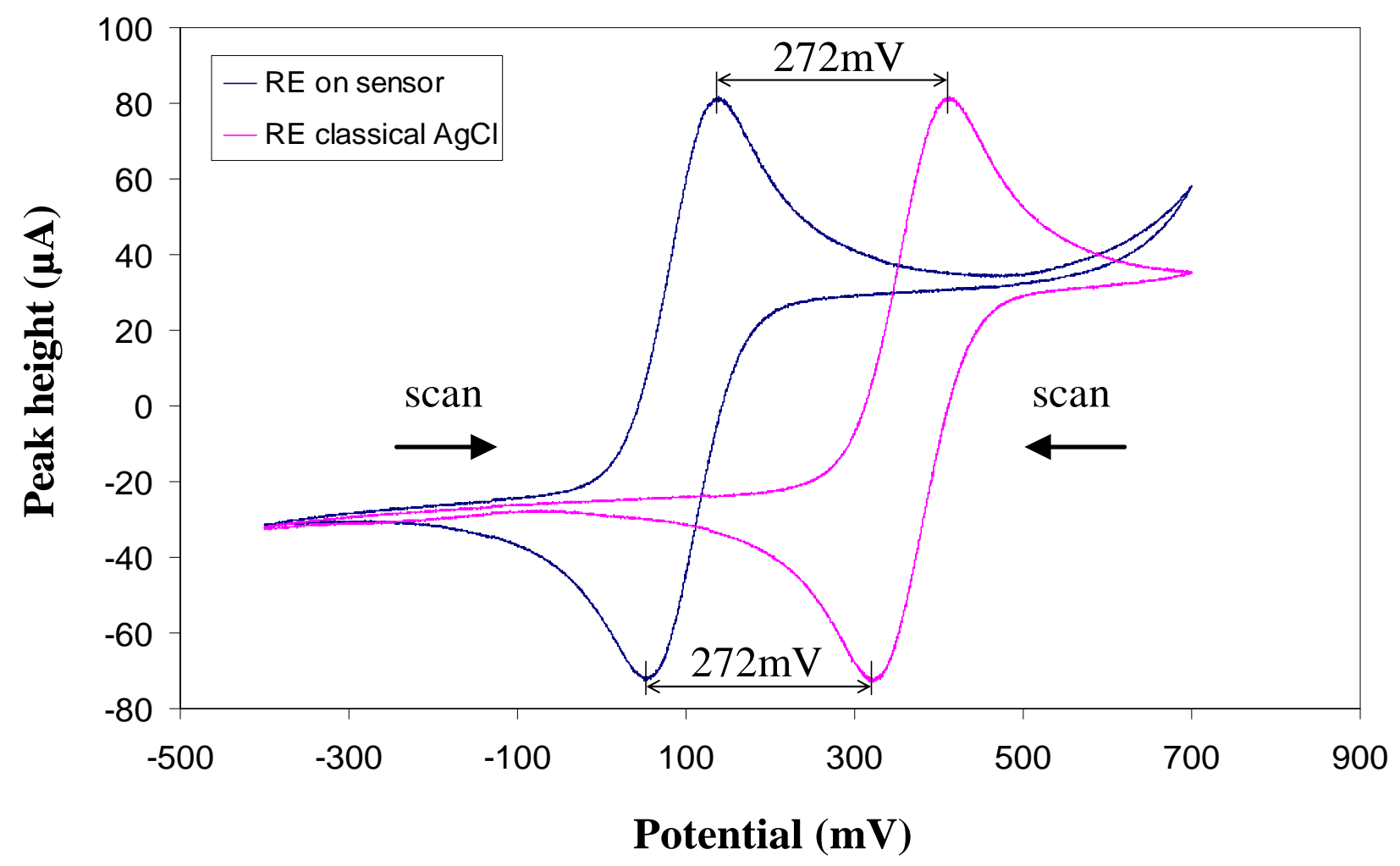

Figure 2. Calibration of TFT reference electrode against saturated Ag/AgCl electrode.

\subsection{Electrochemical experiments}

Fabricated TFT sensor with Au working electrode, Ag reference and auxiliary electrode was fitted into rotating vessel connector according to Fig. 3 and then placed into rotating vessel cell with background electrolyte. The working volume of the background electrolyte was $10 \mathrm{ml}$. The TFT sensor was connected to analytical potentiostat PT050 (Radiometer Analytical, France) using three-electrode system.

For rotating vessel properties measurement (chapter 3.3) the TFT sensor measurements were performed using cyclic voltammetry within the range of potentials from $-550 \mathrm{mV}$ to $+650 \mathrm{mV}$ with 25 $\mathrm{mV} / \mathrm{s}$ scan rate. There were made several experiments with changing the rotation speed and looking for suitable position of the sensor. The main emphasis was focused on the best current response with low noise of the sensor under test.

The differential pulse voltammetry (DPV) was used for detection of cadmium. DPV parameters were as follows: the initial potential of $0 \mathrm{mV}$, the end potential $-1100 \mathrm{mV}$, the modulation time $0.057 \mathrm{~s}$, the time interval $0.2 \mathrm{~s}$, the step potential $1.05 \mathrm{mV} / \mathrm{s}$, the modulation amplitude of $25 \mathrm{mV}$.

\subsection{Flow analysis}

Other experiments were done with another types of commonly used electrochemical arrangements for comparison (standard laboratory non stirred cell, stirred cell by glass rod providing by electromotor, channel electrode cell (BVT Technologies, CZ) with peristaltic pump (Masterflex, Barnant Company, 
USA), channel electrode cell with microperistaltic pump (both BVT Technologies, CZ ), Micro Flow system (BVT Technologies, CZ ). All the measurements were provided at room temperature $\left(25^{\circ} \mathrm{C}\right)$.

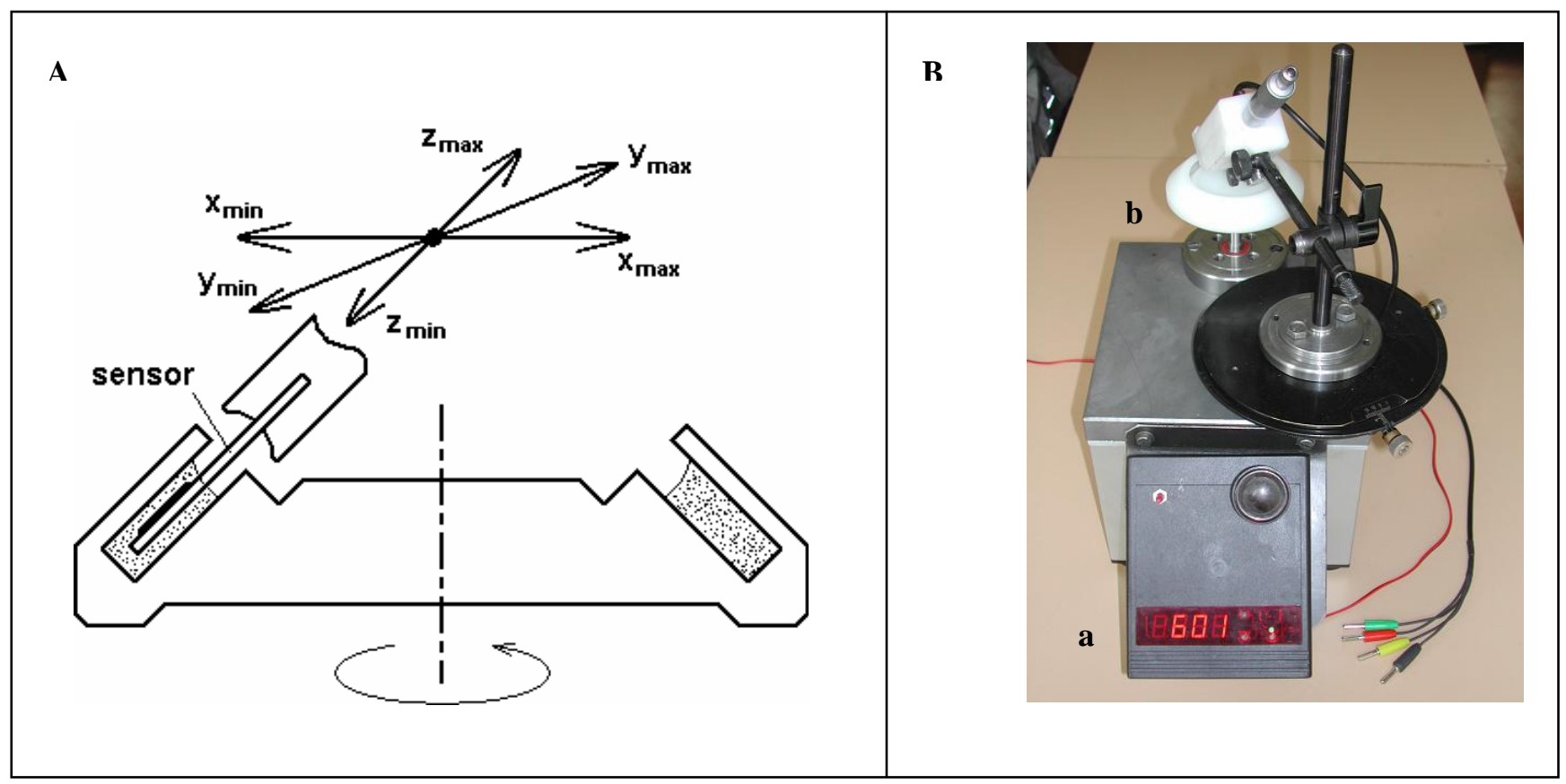

Figure 3. Scheme of the suggested device (A). Photography of prototype of new electrochemical device (B) revolution regulator (a) and positioning of the sensor, fine 3-axis positioning of the sensor (b).

\section{Results and discussion}

\subsection{Construction of screen printed electrode}

Primarily, we attempted to design a thick-film sensor for basic electrochemical measurements. The basic shape of the sensor and its electrode arrangement is shown in Fig. 1. This sensor uses Ag based paste for leads and contacts. The reference electrode material is Ag based paste which can be electrochemically modified with AgCl layer after the main sensor fabrication process [51]. Auxiliary electrode material is also Ag based paste. The material of each electrode can be changed by a use of another type of the paste, whereas the working electrode material depends on the application [52-55]. This sensor can be also used as biosensor substrate for enzyme layer deposition [56,57]. The main advantage of this solution is a possibility of a working electrode material change during the fabrication process and the sensor compatibility with others electrochemical analytical devices that are commonly used in our laboratory to ensure the reproducible conditions during the measurement.

\subsection{New electrochemical analytical device}

To our knowledge, rotating disc electrode (RDE) is the most expansively used experimental arrangement in fabrication of electrochemical sensors ensuring electrode reaction execution with welldescribed hydrodynamic conditions and mass transport intensity [51]. From the point of experimental 
data processing view, possibility of an accurate subtraction of additional response that is given by kinetic of own electrode reaction and by breaking effect of the mass transport from a volume of the electrolyte to the electrode surface are the main advantages of RDE. However, the RDE does not allow the study of more complicated topologies of electrodes from macroscopic point of view [58], therefore, if we use RDE, we can work with one or a very few electrodes only. This usually causes to do one species analysis in one pass only so the necessity of more species analysis leads to time wasting. Besides that the RDE needs either a study of material deposited on standard electrode or a work with exchangeable heads. Thus, the cell construction is very complex, expensive and often it is difficult to put sensor or electrode in the same position as it was in previous step of measurement. Very similar situation comes up in a case of a use of the Wall-jet experimental arrangement [59] or the channel electrode arrangement with possibility of electrode arrays utilization. The device is equipped with exchangeable rotating vessel and static holder with connector for inserting exchangeable TFT sensor. If the vessel would be polluted, this vessel could be exchange for other one, whereas the measurement could follow. We presume that when the sensor is placed closely to conic wall of the rotating vessel, well and reproducible defined flow should be arisen in liquid layer between the wall and the TFT sensor (on the sensor's electrode surface).

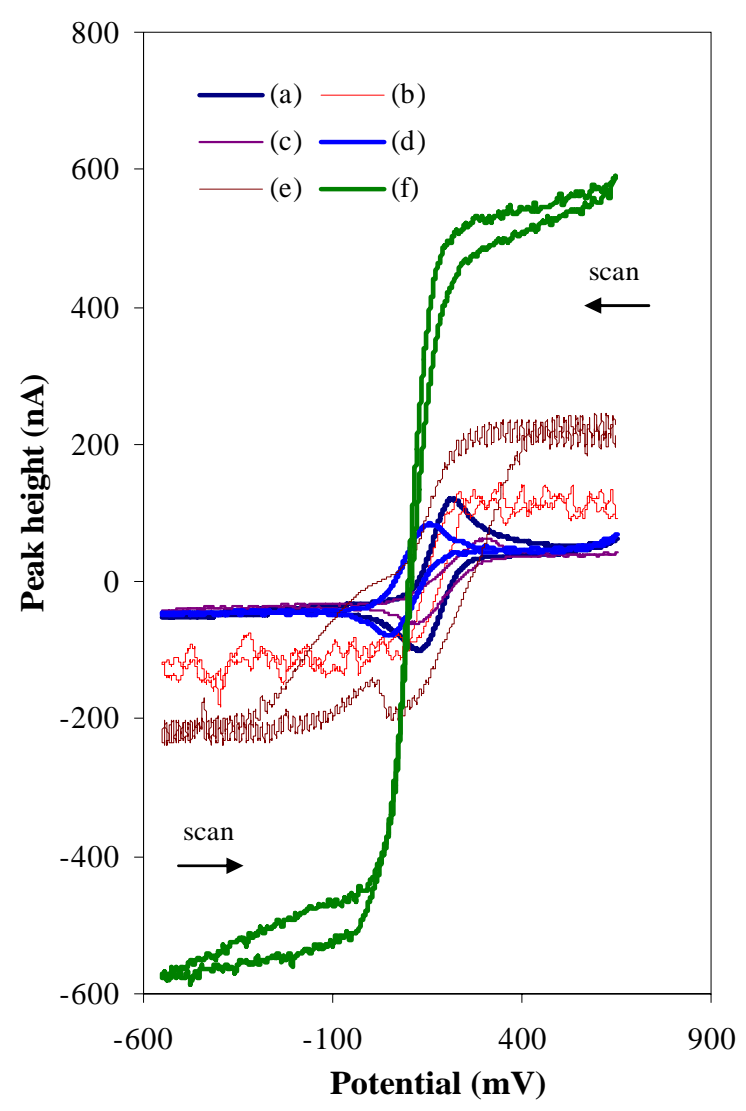

Figure 4. Cyclic voltammograms of $0.1 \mathrm{M}$ potassium ferrocyanide-ferricyanide measured by TFT sensor with gold working electrode at different arrangements of electrochemical analysis in combination with flow of background electrolyte: (a) non stirred arrangement; (b) continual stirred arrangement; (c) application peristaltic pump at flow of $0.4 \mathrm{ml} / \mathrm{min}$; (d) microperistaltic pump at flow of $100 \mu \mathrm{l} / \mathrm{min}$; (e) micro-flow system at flow of $10 \mu \mathrm{l} / \mathrm{min}$; (f) rotating vessel at $175 \mathrm{rpm}$. Background electrolyte $0.1 \mathrm{M} \mathrm{KCl}$. CV parameters were as follows: the initial potential of $-550 \mathrm{mV}$, the end 
potential $650 \mathrm{mV}$, scan rate $25 \mathrm{mV} / \mathrm{s}$. Working electrode surface area: $2.075 \mathrm{~mm}^{2}$, the working volume of the background electrolyte was $10 \mathrm{ml}$. For other details see "Experimental" section.

The device can use TFT sensors without any modification and also allows doing sensor tests during technology process of its fabrication according to Fig. 1. It is possible to take the TFT sensor out of the device and then continue with deposition of next materials on the electrode surface. This process is impossible to do, of we use RDE. The new device can use electrode arrays that allow simultaneous analysis processing of more species, which is crucial advantage of this device.

Main advantages (+) and disadvantages (-) of the new electrochemical analytical device can be summarized as follows:

+ possibility of a complex electrode design integration (electrode arrays)

+ certain unchangeable hydrodynamic conditions

+ easy electrodes exchanging

+ ensuring of device purity is achieved by exchanging of all contaminated components

+ smoothness of electrode is achieved by proper electrode choose

+ small amount of analyzed solution

- dependence on constant rotation speed - this problem was resolved by rotation speed setting and geometrical arrangement changing in this work

- $\quad$ difficult implementation of inert atmosphere - can be solved by construction of the device

\subsection{Prototype of new electrochemical device}

The prototype of new electrochemical analytical device shown in Fig. 3 was improved for the practical tests and measurements. We showed that the device gives similar results as others common used devices. There was also mentioned above the problem with rotating vessel vibrations that affect the sensors' output current response. This problem was caused by wrong axial alignment of the vessel. Therefore we designed and made the new device prototype. The vibration influence was partially suppressed by means of better construction design and better fabrication accuracy. The vessel diameter is two times bigger than it was in previous prototypes, so the tip speed is the same with lower angular velocity. A noise caused by vibrations was decreased also.

In the following experiments the comparison of commonly used electrochemical arrangements such as non-stirred arrangement, un-reproducible stirred arrangement, channel electrode with peristaltic pump arrangement, wall-jet based Micro Flow System with the suggested device were made. The measurements were done by TFT sensor with gold working, reference (Ag/AgCl) and carbon auxiliary electrode. We were able to obtain characteristics cyclic voltammograms by the mentioned electrochemical devices (Fig. 4). If we analysed the non-stirred solution, the signal appeared at potential of $150 \mathrm{mV}$. On the other hand, during analysis the stirred solution the current response was interfered by convection. Moreover, if we utilized different flow arrangements, we observed well developed and reproducible voltammograms (Fig. 4). Pulsing of the solution analysed caused by pump is the disadvantage of these arrangements. The advantage of these arrangements expressed markedly in increase in peak height with slight shift to more negative potentials. The observed changes could be associated with hydrodynamic processes taking place closely to TFT sensor. In spite of this disadvantage it clearly follows from the results obtained that well reproducible results can be obtained 
by means of this new analytical device in comparison with other ones. Thus the device appears to be very suitable for the utilization with thick-film chemical sensors or biosensors.

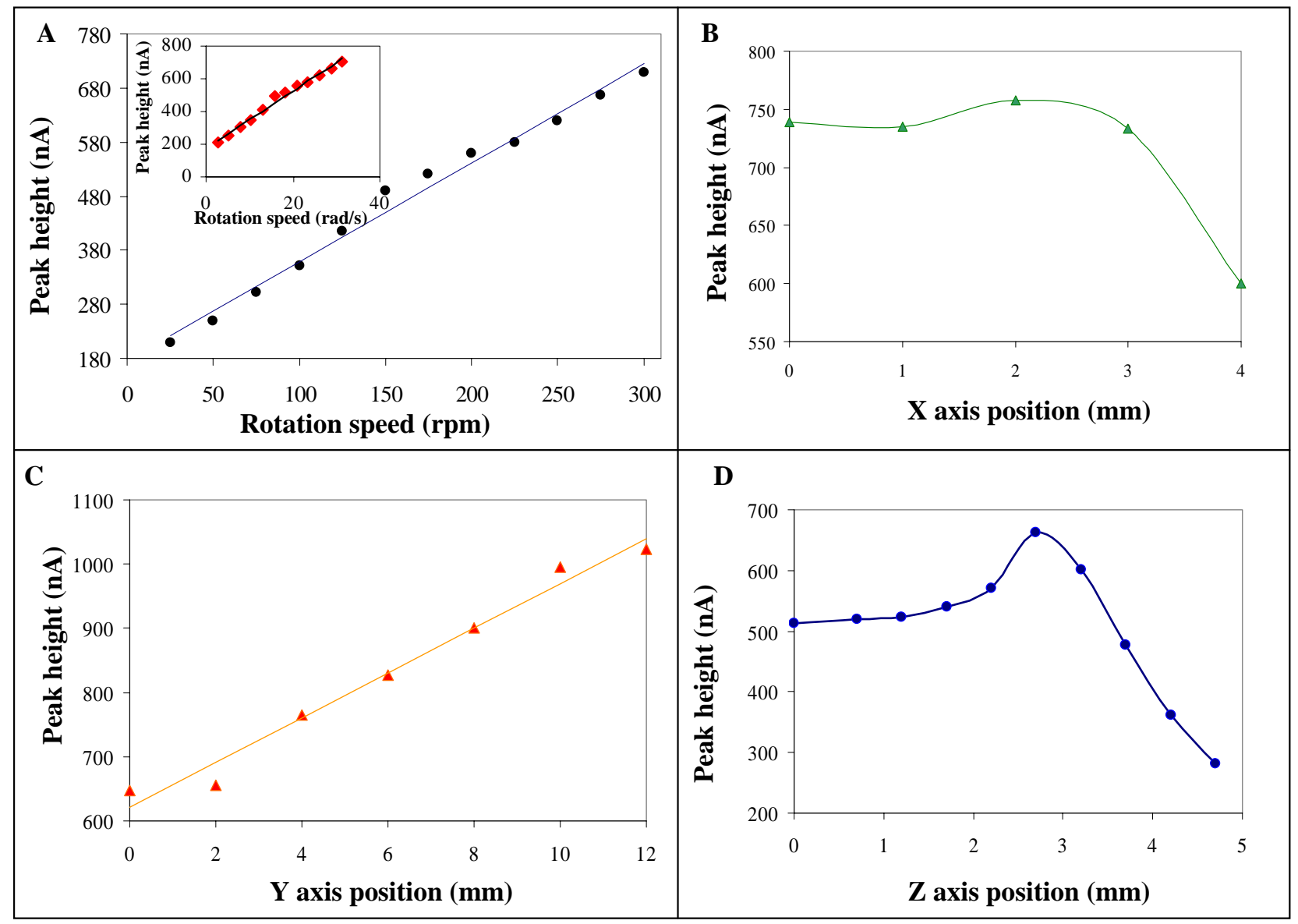

Figure 5. Changes in peak height of $0.1 \mathrm{M}$ potassium ferrocyanide-ferricyanide measured by TFT sensor gold working electrode at different conditions: rotation speed (rpm), in inset: (rad/s) (A); x axis position (B); y axis position (C); z axis position (D). For other details see Fig. 3 and "Experimental" section.

The new device prototype is equipped with rotation speed measurement that ensures reproducible conditions during each analytical measurement. The rotation speed regulation is not necessary due to low hydraulic friction (the rotations are constant for all measurement). This prototype also allows the fine 3-axis positioning of the sensor in the vessel (Fig. 3). This is an advantage in the case of use of different types of sensors which can have different optimal measurement conditions. We assume that we should obtain laminar flow along the electrodes so the sensor response would be very clear in the arrangement, where the TFT sensor has the electrode layer positioned very close to rotating vessel wall (xmin) according to Fig. 3.

The position of the sensor was set to a middle value of the maximum range and the corresponding current was read at potential of $300 \mathrm{mV}$ (the negative area has similar dependence) due to measurement of analytical device properties. The dependence of output current responses on rotation speed is shown in Fig. 5. The results show that the sensors' output current responses increased three 
times in comparison with the measurement done at lowest achievable rotation speed. Unfortunately the problem with noise was occurred again. The noise is appeared from $150 \mathrm{rpm}$ and dramatically grows up from $200 \mathrm{rpm}$. Therefore the maximum acceptable rotation speed was $175 \mathrm{rpm}$ or $150 \mathrm{rpm}$ respectively. We followed by optimizing of a suitable position of the sensor in the vessel. The rotation speed was set to $300 \mathrm{rpm}$ for better evaluation of influence of the sensor position to the output current response (Fig. 5A). Next, the diffusion coefficient for potassium ferrocyanide-ferricyanide at $298 \mathrm{~K}$ was determined. A plot of the limiting current observed during reduction vs the square root of the rate of rotation (inset in Fig. 5A) is linear, and therefore, the "Levich" equation can be employed to determine the diffusion coefficient as follows [60]:

$$
I_{\lim }=0.62 \times n \times F \times A \times c \times D^{2 / 3} \times v^{-1 / 6} \times \omega^{1 / 2}
$$

In this equation the mass-transport-controlled limiting current for the reduction, $\mathrm{I}_{\text {lim, }}$, is related to the number of electrons transferred per molecule diffusing to the electrode surface, n, the Faraday constant, $\mathrm{F}$, the electrode area, $\mathrm{A}$, the bulk concentration of potassium ferrocyanide-ferricyanide, $\mathrm{c}$, the diffusion coefficient, D, the viscosity at $298 \mathrm{~K} \mathrm{v}$, and $\omega$, the rate of rotation. From data in inset in Fig. 5A the diffusion coefficient at a temperature of $25^{\circ} \mathrm{C}(298 \mathrm{~K})$ is $\mathrm{D}=3.3 \times 10^{-11} \mathrm{~m}^{2} \cdot \mathrm{s}^{-1}$.

Dependence of output current response on $\mathrm{x}, \mathrm{y}$ and $\mathrm{z}$ axis position is shown in the Fig. 5B,C,D. It is obvious that the positioning of the sensor in $\mathrm{x}$ axis does not have so high influence as the rotation speed but it is necessary to find the compromise between the output current response and the noise. The lowest noise was achieved at $\mathrm{x}_{\max }$ position. Moreover, it was very interesting for us that the output current response was not linear with $\mathrm{x}$ position. In the case of $\mathrm{y}$ axis position the situation is a little different. The output current response increases with an increasing y position but the noise is more or less the same in all range (Fig. 5C). It follows from the results obtained that the response quality is not determined by a laminar flow. The best result was achieved in $\mathrm{y}_{\max }$ position (the one against the direction of the rotation). The dependence of output current response on $\mathrm{z}$ axis from 0 to $2.7 \mathrm{~mm}$ is shown in Fig 5D. In this case we presumed that there would not be any response dependence. In contrast with our presumption we observed the changes in response with increasing $\mathrm{z}$ axis position. If the sensor is more stick-out from the electrolyte the response is higher. The noise decreased with increasing $\mathrm{z}$ position and almost disappeared at the highest $\mathrm{z}$ axis value.

\subsection{Heavy metals detection}

The suggested device was utilized for detection of cadmium(II) ions (Fig. 6A). Particularly, we utilized TFT sensor with gold working electrode. We obtained signals of cadmium(II) ions at potential of $-920 \mathrm{mV}$, which means shift of the signals for more than $300 \mathrm{mV}$ to negative potentials in comparison with detection of cadmium on the surface of hanging mercury drop electrode. The result probably relates with different electrode material and with physically-chemical changes on the surface of working electrode connected to hydrodynamic properties of the solution analysed. The changes in height of cadmium signals with its increasing concentration were studied within the range from 0 to $150 \mu \mathrm{mol} / \mathrm{L}$. We obtained linear calibration curve with equation as follows: $\mathrm{y}=0.0383 \mathrm{x}+0.0765 ; \mathrm{R}^{2}$ $=0.989$ (Fig. 6B). The detection limit expressed as $3 \mathrm{~S} / \mathrm{N}$ was $500 \mathrm{nmol} / \mathrm{L}$ with relative standard 
deviation about $10 \%$. It clearly follows from the results obtained that the new electrochemical analytical device for controlled flow electrolyte to sensor works properly and gives us similar results as others experimental arrangements and could be used for environmental and bio-analytical purposes.

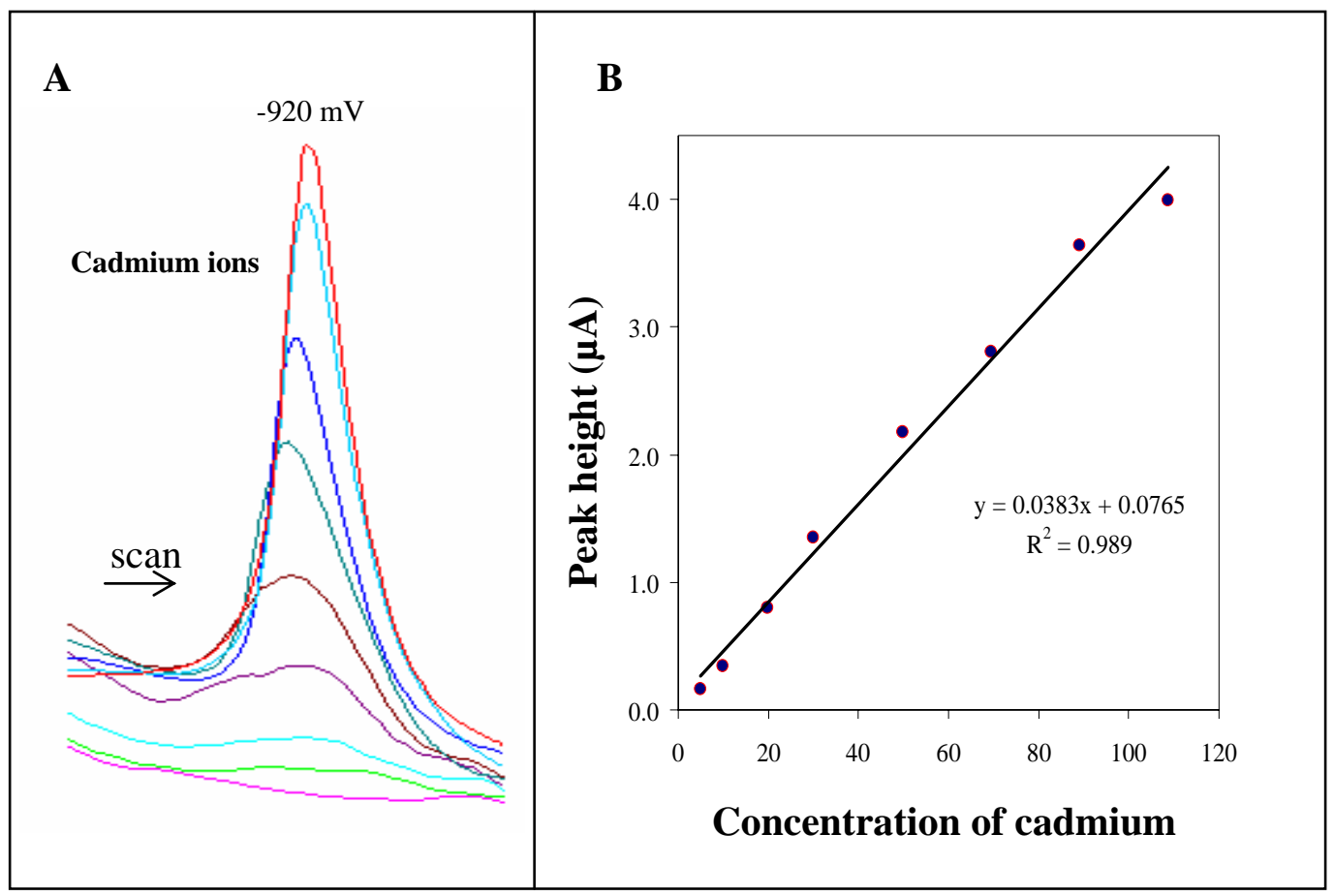

Figure 6. Differential pulse voltammograms of cadmium(II) ions (5 - $120 \mu \mathrm{M})$ measured by TFT sensor, gold working electrode carbon auxiliary and $\mathrm{Ag} / \mathrm{AgCl}$ reference electrode. (A). Dependence of cadmium ions signals on its concentration (B). Background electrolyte $0.1 \mathrm{M} \mathrm{KCl}$. Rotating Vessel response (50 rpm), x axis position $2 \mathrm{~mm}$; y axis position $6 \mathrm{~mm}$; z axis position $2.7 \mathrm{~mm}$, working electrode surface area: $2.075 \mathrm{~mm}^{2}$, the working volume of the background electrolyte was $10 \mathrm{ml}$. DPV parameters were as follows: the initial potential of $0 \mathrm{mV}$, the end potential $-1100 \mathrm{mV}$, the modulation time $0.057 \mathrm{~s}$, the time interval $0.2 \mathrm{~s}$, the step potential $1.05 \mathrm{mV} / \mathrm{s}$, the modulation amplitude of $25 \mathrm{mV}$.

\section{Conclusions}

We found out that the new device with controlled flow of electrolyte to sensor worked properly and gave satisfactory results. Trace analysis of cadmium shows that new device prototype gives similar information as others common used electrochemical arrangements. Moreover, it clearly follows from the results obtained that lower noise is observed in comparison with commonly used electrochemical devices.. Noise also plays a significant role in an experiment setup. The dependences of current responses on the sensor position show that it is possible to reach very good current response progress without or with very low noise by suitable combination of sensor position in all axes in the rotating vessel. The results indicate that it is necessary to put emphasis on flow systems working with biosensors or chemical sensor where the output current response can be multiplied. In addition, the better the detection limit, accuracy, reliability and/or reproducibility of measurements can be achieved 


\section{Acknowledgements}

This work was partially supported by Grant Agency of The Academy of Science, Czech Republic under the contract 1QS201710508 Impedimetric microsensors with nanomachined surface of electrodes and Czech Ministry of Education in the frame of Research Plan MSM 0021630503 MIKROSYN. New electrochemical analytical device was registered for patenting with number PV 2001-4096. The authors also wish to thanks Grant Agency of the Czech Republic GACR 525/04/P132, INCHEMBIOL 0021622412 and M06030.

\section{References}

1. Martinez-Manez, R.; Soto, J.; Garcia-Breijo, E.; Gil, L.; Ibanez, J.; Llobet, E. An "electronic tongue" design for the qualitative analysis of natural waters. Sens. Actuator B-Chem. 2005, 104, 302-307.

2. Honeychurch, K.C.; Hart, J.P. Screen-printed electrochemical sensors for monitoring metal pollutants. Trac-Trends Anal. Chem. 2003, 22, 456-469.

3. Ibanez-Garcia, N.; Mercader, M.B.; da Rocha, Z.M.; Seabra, C.A.; Gongora-Rubio, M.R.; Chamarro, J.A. Continuous flow analytical microsystems based on low-temperature co-fired ceramic technology. Integrated potentiometric detection based on solvent polymeric ion-selective electrodes. Anal. Chem. 2006, 78, 2985-2992.

4. Liao, W.Y.; Chou, T.C. Fabrication of a planar-form screen-printed solid electrolyte modified $\mathrm{Ag} / \mathrm{AgCl}$ reference electrode for application in a potentiometric biosensor. Anal. Chem. 2006, 78, 4219-4223.

5. Pumera, M.; Merkoci, A.; Alegret, S. New materials for electrochemical sensing VII. Microfluidic chip platforms. Trac-Trends Anal. Chem. 2006, 25, 219-235.

6. Wang, J.; Tian, B.M. Screen-Printed Stripping Voltammetric Potentiometric Electrodes for Decentralized Testing of Trace Lead. Anal. Chem. 1992, 64, 1706-1709.

7. Wang, J.; Lu, J.M.; Tian, B.M.; Yarnitzky, C. Screen-Printed Ultramicroelectrode Arrays for onSite Stripping Measurements of Trace-Metals. J. Electroanal. Chem. 1993, 361, 77-83.

8. Sato, N.; Okuma, H. Amperometric simultaneous sensing system for D-glucose and L-lactate based on enzyme-modified bilayer electrodes. Anal. Chim. Acta 2006, 565, 250-254.

9. Ghamouss, F.; Ledru, S.; Ruille, N.; Lantier, F.; Boujtita, M. Bulk-modified modified screenprinting carbon electrodes with both lactate oxidase (LOD) and horseradish peroxide (HRP) for the determination of L-lactate in flow injection analysis mode. Anal. Chim. Acta 2006, 570, 158164.

10. Desmond, D.; Lane, B.; Alderman, J.; Hill, M.; Arrigan, D.W.M.; Glennon, J.D. An environmental monitoring system for trace metals using stripping voltammetry. Sens. Actuator BChem. 1998, 48, 409-414.

11. Palchetti, I.; Cagnini, A.; Mascini, M.; Turner, A.P.F. Characterisation of screen-printed electrodes for detection of heavy metals. Mikrochim. Acta 1999, 131, 65-73.

12. Pumera, M. Analysis of nerve agents using capillary electrophoresis and laboratory-on-a-chip technology. J. Chromatogr. A 2006, 1113, 5-13. 
13. Pumera, M.; Merkoci, A.; Alegret, S. Carbon nanotube-epoxy composites for electrochemical sensing. Sens. Actuator B-Chem. 2006, 113, 617-622.

14. Zhong, X.; Yuan, R.; Chai, Y.Q.; Liu, Y.; Dai, J.Y.; Tang, D.P. Glucose biosensor based on selfassembled gold nanoparticles and double-layer 2d-network (3-mercaptopropyl)-trimethoxysilane polymer onto gold substrate. Sens. Actuator B-Chem. 2005, 104, 191-198.

15. Sun, X.Y.; Xu, F.Q.; Li, Z.M.; Zhang, W.H. Cyclic voltammetry for the fabrication of high dense silver nanowire arrays with the assistance of AAO template. Mater. Chem. Phys. 2005, 90, 69-72.

16. Homola, J.; Yee, S.S.; Gauglitz, G. Surface plasmon resonance sensors: review. Sens. Actuator BChem. 1999, 54, 3-15.

17. Buhlmann, P.; Pretsch, E.; Bakker, E. Carrier-based ion-selective electrodes and bulk optodes. 2. Ionophores for potentiometric and optical sensors. Chem. Rev. 1998, 98, 1593-1687.

18. Kang, B.S.; Wang, H.T.; Tien, L.C.; Ren, F.; Gila, B.P.; Norton, D.P.; Abernathy, C.R.; Lin, J.S.; Pearton, S.J. Wide bandgap semiconductor nanorod and thin film gas sensors. Sensors 2006, 6, 643-666.

19. Diculescu, V.C.; Paquim, A.M.C.; Brett, A.M.O. Electrochemical DNA sensors for detection of DNA damage. Sensors 2005, 5, 377-393.

20. Grimes, C.A.; Mungle, C.S.; Zeng, Z.F.; Jain, M.K.; Dreschel, W.R.; Paulose, M.; Ong, K.G. Wireless magnetoelastic resonance sensors: A critical review. Sensors 2002, 2, 294-313.

21. Adam, V.; Petrlova, J.; Potesil, D.; Zehnalek, J.; Sures, B.; Trnkova, L.; Jelen, F.; Kizek, R. Study of metallothionein modified electrode surface behaviour in the presence of heavy metal ions biosensor. Electroanalysis 2005, 17, 1649-1657.

22. Adam, V.; Zehnalek, J.; Petrlova, J.; Potesil, D.; Sures, B.; Trnkova, L.; Jelen, F.; Vitecek, J.; Kizek, R. Phytochelatin modified electrode surface as a sensitive heavy metal ions biosensor. Sensors 2005, 5, 70-84.

23. Petrlova, J.; Potesil, D.; Zehnalek, J.; Sures, B.; Adam, V.; Trnkova, L.; Kizek, R. Cisplatin electrochemical biosensor. Electrochim. Acta 2006, 51, 5169-5173.

24. Palecek, E.; Kizek, R.; Havran, L.; Billova, S.; Fojta, M. Electrochemical enzyme-linked immunoassay in a DNA hybridization sensor. Anal. Chim. Acta 2002, 469, 73-83.

25. Krizkova, S.; Adam, V.; Petrlova, J.; Zitka, O.; Stejskal, K.; Zehnalek, J.; Sures, B.; Trnkova, L.; Beklova, M.; Kizek, R. A suggestion of electrochemical biosensor for study of Platinum(II)-DNA interactions. Electroanalysis 2006, in press.

26. Kizek, R.; Vacek, J.; Trnkova, L.; Klejdus, B.; Kuban, V. Electrochemical biosensors in agricultural and environmental analysis. Chem. Listy 2003, 97, 1003-1006.

27. Kizek, R.; Trnkova, L.; Sevcikova, S.; Smarda, J.; Jelen, F. Silver electrode as a sensor for determination of zinc in cell cultivation medium. Anal. Biochem. 2002, 301, 8-13.

28. Adam, V.; Petrlova, J.; Potesil, D.; Lubal, P.; Zehnalek, J.; Sures, B.; Kizek, R. New electrochemical biosensor to determine platinum cytostatics to DNA structure. Chem. Listy 2005, 99, 353-393.

29. Supalkova, V.; Petrek, J.; Havel, L.; Krizkova, S.; Petrlova, J.; Adam, V.; Potesil, D.; Babula, P.; Beklova, M.; Horna, A.; Kizek, R. Electrochemical Sensors for Detection of Acetylsalicylic Acid. Sensors 2006, 11, 1483-1497. 
30. Babula, P.; Huska, D.; Hanustiak, P.; Baloun, J.; Krizkova, S.; Adam, V.; Hubalek, J.; Havel, L.; Zemlicka, M.; Horna, A.; Beklova, M.; Kizek, R. Flow Injection Analysis Coupled with Carbon Electrodes as the Tool for Investigation of Affecting and Content of Naphthoquinones in Biological Samples. Sensors 2006, 11, 1466-1482.

31. Singh, K.P.; Mohan, D.; Sinha, S.; Dalwani, R. Impact assessment of treated/untreated wastewater toxicants discharged by sewage treatment plants on health, agricultural, and environmental quality in the wastewater disposal area. Chemosphere 2004, 55, 227-255.

32. Endo, T.; Haraguchi, K.; Cipriano, F.; Simmonds, M.P.; Hotta, Y.; Sakata, M. Contamination by mercury and cadmium in the cetacean products from Japanese market. Chemosphere 2004, 54, 1653-1662.

33. Zehnalek, J.; Adam, V.; Kizek, R. Influence of heavy metals on production of protecting compounds in agriculture plants. Listy Cukrov. 2004, 120, 222-224.

34. Witkiewicz-Kucharczyk, A.; Bal, W. Damage of zinc fingers in DNA repair proteins, a novel molecular mechanism in carcinogenesis. Toxicol. Lett. 2006, 162, 29-42.

35. Kopera, E.; Schwerdtle, T.; Hartwig, A.; Bal, W. Co(II) and Cd(II) substitute for Zn(II) in the zinc finger derived from the DNA repair protein XPA, demonstrating a variety of potential mechanisms of toxicity. Chem. Res. Toxicol. 2004, 17, 1452-1458.

36. Petering, D.H.; Huang, M.; Moteki, S.; Shaw, C.F. Cadmium and lead interactions with transcription factor IIIA from Xenopus laevis: a model for zinc finger protein reactions with toxic metal ions and metallothionein. Mar. Environ. Res. 2000, 50, 89-92.

37. Hanas, J.S.; Gunn, C.G. Inhibition of transcription factor IIIA-DNA interactions by xenobiotic metal ions. Nucleic Acids Res. 1996, 24, 924-930.

38. Giaginis, C.; Gatzidou, E.; Theocharis, S. DNA repair systems as targets of cadmium toxicity. Toxicol. Appl. Pharmacol. 2006, 213, 282-290.

39. Il'yasova, D.; Schwartz, G.G. Cadmium and renal cancer. Toxicol. Appl. Pharmacol. 2005, 207, 179-186.

40. Ikeda, M.; Ezaki, T.; Tsukahara, T.; Moriguchi, J. Dietary cadmium intake in polluted and nonpolluted areas in Japan in the past and in the present. Int. Arch. Occup. Environ. Health 2004, 77, 227-234.

41. Rikans, L.E.; Yamano, T. Mechanisms of cadmium-mediated acute hepatotoxicity. J. Biochem. Mol. Toxicol. 2000, 14, 110-117.

42. Zehnalek, J.; Stejskal, K.; Adam, V.; Havel, L.; Trnkova, L.; Klejdus, B.; Kuban, V.; Kizek, R. The effect of cadmium ions on maize (Zea mays L.) revealed by differential pulse anodic stripping voltammetry and liquid chromatography mass spectrometry. Int. J. Environ. Anal. Chem. 2006, submitted.

43. Prusa, R.; Kizek, R.; Vacek, J.; Trnkova, L.; Zehnalek, J. Study of relationship between metallothionein and heavy metals by CPSA method. Clin. Chem. 2004, 50, A28-A29.

44. Klejdus, B.; Zehnalek, J.; Adam, V.; Petrek, J.; Kizek, R.; Vacek, J.; Trnkova, L.; Rozik, R.; Havel, L.; Kuban, V. Sub-picomole high-performance liquid chromatographic/mass spectrometric determination of glutathione in the maize (Zea mays L.) kernels exposed to cadmium. Anal. Chim. Acta 2004, 520, 117-124. 
45. Lo Coco, F.; Monotti, P.; Cozzi, F.; Adami, G. Determination of cadmium and lead in fruit juices by stripping chronopotentiometry and comparison of two sample pretreatment procedures. Food Control 2006, 17, 966-970.

46. Kenduzler, E. Determination of cadmium(II) in water and soil samples after preconcentration with a new solid phase extractor. Sep. Sci. Technol. 2006, 41, 1645-1659.

47. Dong, H.M.; Zheng, H.; Lin, L.; Ye, B.X. Determination of thallium and cadmium on a chemically modified electrode with Langmuir-Blodgett film of p-allylcalix 4 arene. Sens. Actuator B-Chem. 2006, 115, 303-308.

48. do Nascimento, P.C.; Marques, M.D.; Hilgemann, M.; de Carvalho, L.M.; Bohrer, D.; Pomblum, S.G.; Schirmer, S. Simultaneous determination of cadmium, copper, lead and zinc in amino acid parenteral nutrition solutions by anodic stripping voltammetry and sample digestion by UV irradiation. Anal. Lett. 2006, 39, 777-790.

49. Ensafi, A.A.; Khayamian, T.; Benvidi, A.; Mirmomtaz, E. Simultaneous determination of copper, lead and cadmium by cathodic adsorptive stripping voltammetry using artificial neural network. Anal. Chim. Acta 2006, 561, 225-232.

50. Davis, A.C.; Wu, P.; Zhang, X.F.; Hou, X.D.; Jones, B.T. Determination of cadmium in biological samples. Appl. Spectrosc. Rev. 2006, 41, 35-75.

51. Lanz, M.; Schurch, D.; Calzaferri, G. Photocatalytic oxidation of water to O-2 on AgCl-coated electrodes. J. Photochem. Photobiol. A-Chem. 1999, 120, 105-117.

52. Wohlstadter, J.N.; Wilbur, J.L.; Sigal, G.B.; Biebuyck, H.A.; Billadeau, M.A.; Dong, L.W.; Fischer, A.B.; Gudibande, S.R.; Jamieson, S.H.; Kenten, J.H.; Leginus, J.; Leland, J.K.; Massey, R.J.; Wohlstadter, S.J. Carbon nanotube-based biosensor. Adv. Mater. 2003, 15, 1184-+.

53. Kroger, S.; Turner, A.P.F.; Mosbach, K.; Haupt, K. Imprinted polymer based sensor system for herbicides using differential-pulse voltammetry on screen printed electrodes. Anal. Chem. 1999, 71, 3698-3702.

54. Li, J.; Tan, S.N.; Ge, H.L. Silica sol-gel immobilized amperometric biosensor for hydrogen peroxide. Anal. Chim. Acta 1996, 335, 137-145.

55. Shortreed, M.; Bakker, E.; Kopelman, R. Miniature sodium-selective ion-exchange optode with fluorescent $\mathrm{pH}$ chromoionophores and tunable dynamic range. Anal. Chem. 1996, 68, 2656-2662.

56. Liu, Y.; Lu, H.J.; Zhong, W.; Song, P.Y.; Kong, J.L.; Yang, P.Y.; Girault, H.H.; Liu, B.H. Multi layer-assembled microchip for enzyme immobilization as reactor toward low-level protein identification. Anal. Chem. 2006, 78, 801-808.

57. Zucolotto, V.; Pinto, A.P.A.; Tumolo, T.; Moraes, M.L.; Baptista, M.S.; Riul, A.; Araujo, A.P.U.; Oliveira, O.N. Catechol biosensing using a nanostructured layer-by-layer film containing Clcatechol 1,2-dioxygenase. Biosens. Bioelectron. 2006, 21, 1320-1326.

58. Wapner, K.; Schoenberger, B.; Stratmann, A.; Grundmeier, G. Height-regulating scanning Kelvin probe for simultaneous measurement of surface topology and electrode potentials at buried polymer/metal interfaces. J. Electrochem. Soc. 2005, 152, E114-E122.

59. Lindgren, A.; Munteanu, F.D.; Gazaryan, I.G.; Ruzgas, T.; Gorton, L. Comparison of rotating disk and wall-jet electrode systems for studying the kinetics of direct and mediated electron transfer for horseradish peroxidase on a graphite electrode. J. Electroanal. Chem. 1998, 458, 113120. 
60. Vuorema, A.; John, P.; Jenkins, A.T.A.; Marken, F. A rotating disc voltammetry study of the 1,8dihydroxyanthraquinone mediated reduction of colloidal indigo. J. Solid State Electrochem. 2006, $10,865-871$.

(C) 2006 by MDPI (http://www.mdpi.org). Reproduction is permitted for noncommercial purposes. 